\title{
Determination Amount of Bisphenol A in Drugs and Water Drinking Container in Khartoum State, Sudan
}

\author{
Almoeiz Yousif Hammad, ", Faris Mohamed Awad ${ }^{1}$, Warda Shukrat Alla Abdelgadir ${ }^{2}$ \\ ${ }^{1}$ Department of Biochemistry, Faculty of medicine, Sudan International University, Khartoum, Sudan \\ ${ }^{2}$ Food Research Centre, Ministry of Science and Communication, Khartoum, Sudan
}

Email address:

almoeiz7@hotmail.com (A. Y. Hammad)

\section{To cite this article:}

Almoeiz Yousif Hammad, Faris Mohamed Awad, Warda Shukrat Alla Abdelgadir. Determination Amount of Bisphenol A in Drugs and Water Drinking Container in Khartoum State, Sudan. International Journal of Nutrition and Food Sciences. Vol. 4, No. 6, 2015 , pp. 609-612.

doi: $10.11648 /$ j.ijnfs. 20150406.12

\begin{abstract}
In the early 1930s, the British biochemist Edward Charles Dodds tested BPA as an artificial estrogen, but found it to be 37,000 times less effective than estradiol. In this study, BPA concentration in $\mu \mathrm{g} / \mathrm{L}$ was measured in different drugs and water sample randomly collected from Khartoum state, Sudan to be analyzed by using UV-Vis spectrophotometer instrument (Model - Shimadzu UV2450). The highest concentration was observed in eye and Eyre drops while the lost concentration found in normal saline infusion. Water sample not recorded any amount of BPA.
\end{abstract}

Keywords: Bisphenol A (BPA), UV-Vis Spectrophotometer, Nasal Drop, Eye Drop, Eyre Drop, Normal Saline Infusion

\section{Introduction}

Bisphenol A (BPA) is a carbon-based synthetic compound with the chemical formula $(\mathrm{CH} 3) 2 \mathrm{C}(\mathrm{C} 6 \mathrm{H} 4 \mathrm{OH}) 2$ belonging to the group of diphenylmethane derivatives and bisphenols, with two hydroxyphenyl groups. It is a colorless solid that is soluble in organic solvents, but poorly soluble in water. It has been in commercial use since 1957.BPA is employed to make certain plastics and epoxy resins. BPA-based plastic is clear and tough, and is made into a variety of common consumer goods, such as water bottles, sports equipment, CDs, and DVDs. Epoxy resins containing BPA are used to line water pipes, as coatings on the inside of many food and beverage cans and in making thermal paper such as that used in sales receipts[1]

\subsection{Production of BPA}

Bisphenol A was first synthesized by the Russian chemist A.P. Dianin in 1891. [2][3] This compound is synthesized by the condensation of acetone (hence the suffix A in the name) [4] with two equivalents of phenol. The reaction is catalyzed by a strong acid, such as hydrochloric acid $(\mathrm{HCl})$ or a sulfonated polystyrene resin. Industrially, a large excess of phenol is used to ensure full condensation; the product mixture of the cumene process (acetone and phenol) may also be used as starting material [5].

World production capacity of this compound was 1 million tons in the 1980s, [5] and more than 2.2 million tons in 2009.[6] and thus belongs to the high production volume chemicals. In 2003 , U.S. consumption was 856,000 tons, $72 \%$ of which used to make polycarbonate plastic and $21 \%$ going into epoxy resins. [7] In the U.S., less than $5 \%$ of the BPA produced is used in food contact applications, [8] but remains in the canned food industry and printing applications such as sales receipts. [9][5]

\subsection{Uses of BPA}

Bisphenol A is used primarily to make plastics, and products using bisphenol A-based plastics have been in commercial use since 1957. [10]At least 3.6 million tonnes $(8$ billion pounds) of BPA are used by manufacturers yearly. [11] It is a key monomer in production of epoxy resins [12][13] and in the most common form of polycarbonate plastic. Bisphenol $\mathrm{A}$ is a preferred color developer in carbonless copy paper and thermal point of sale receipt paper. [14][15] When used in thermal paper, BPA is present as "free" (i.e., discrete, non-polymerized) BPA, which is likely to be more available for exposure than BPA polymerized into a resin or plastic.

\subsection{Hazard of $B P A$}

\subsubsection{Human Exposure Sources}

The major human exposure route to BPA is diet, including 
ingestion of contaminated food and water. [16] It is especially likely to leach from plastics when they are cleaned with harsh detergents or when they contain acidic or hightemperature liquids. BPA is used to form epoxy resin coating of water pipes; in older buildings, such resin coatings are used to avoid replacement of deteriorating pipes. At 2009 Health Canada study found that the majority of canned soft drinks it tested had low, but measurable levels of bisphenol A. [17] A study conducted by the University Of Texas School Of Public Health in 2010 found BPA in 63 of 105 samples of fresh and canned foods, including fresh turkey sold in plastic packaging and canned infant formula.

\subsubsection{Health Effect}

[18] Bisphenol $\mathrm{A}$ is an endocrine disruptor that can mimic estrogen and has been shown to cause negative health effects in animal studies. To be specific, bisphenol A closely mimics the structure and function of the hormone estradiol with the ability to bind to and activate the same estrogen receptor as the natural hormone. [19][20][21][22][23] Early developmental stages appear to be the period of greatest sensitivity to its effects, [19] and some studies have linked prenatal exposure to later physical and neurological difficulties. Regulatory bodies have determined safety levels for humans, but those safety levels are currently being questioned or are under review as a result of new scientific studies. [24][25]

\section{Materials and Methods}

\subsection{Samples and Experimental Design}

Seven samples (Drinking water - bad storage-, Drinking

water - good storage-, normal saline infusion, Nasal drop, Eye drop, Eyre drop and Distil water for injection) were obtained randomly from Khartoum state to the Central lab, National Centre for Research, Khartoum.

\subsection{Data Collected}

Spectrometric analysis: $100 \mu \mathrm{l}$ of samples were made up to $3 \mathrm{ml}$ by using ethyl acetate and scanned in the range of $200 \mathrm{~nm}$ to 800 by using UV-Vis spectrophotometer instrument (Model - Shimadzu UV2450). The concentration of BPA in each sample was calculated as follows:

Concentration of sample $=$ (Absorbance of sample /absorbance of standard) X standard concentration

\section{Result and Discussion}

\subsection{Result}

All the samples tested gives absorbance at wave length $280 \mathrm{~nm}$, nasal drops recorded highest concentration wile normal saline infusion recorded the lowest one, the result was given in the table 1 and figure 1.

Table 1: Concentration of BPA.

\begin{tabular}{lll}
\hline No. & Sample & $\begin{array}{l}\text { Concentration of } \\
\text { bisphenol } \mathbf{A} / \boldsymbol{\mu g} / \mathbf{L}\end{array}$ \\
\hline 1 & Drinking water(bad storage) & 0.00 \\
2 & Drinking water (good storage) & 0.00 \\
3 & N.S infusion & 0.01116 \\
4 & Nasal drop & 0.22212 \\
5 & Eye drop & 9.00 \\
6 & Eyre drop & 9.00 \\
7 & Distil water for injection & 0.0153 \\
\hline
\end{tabular}

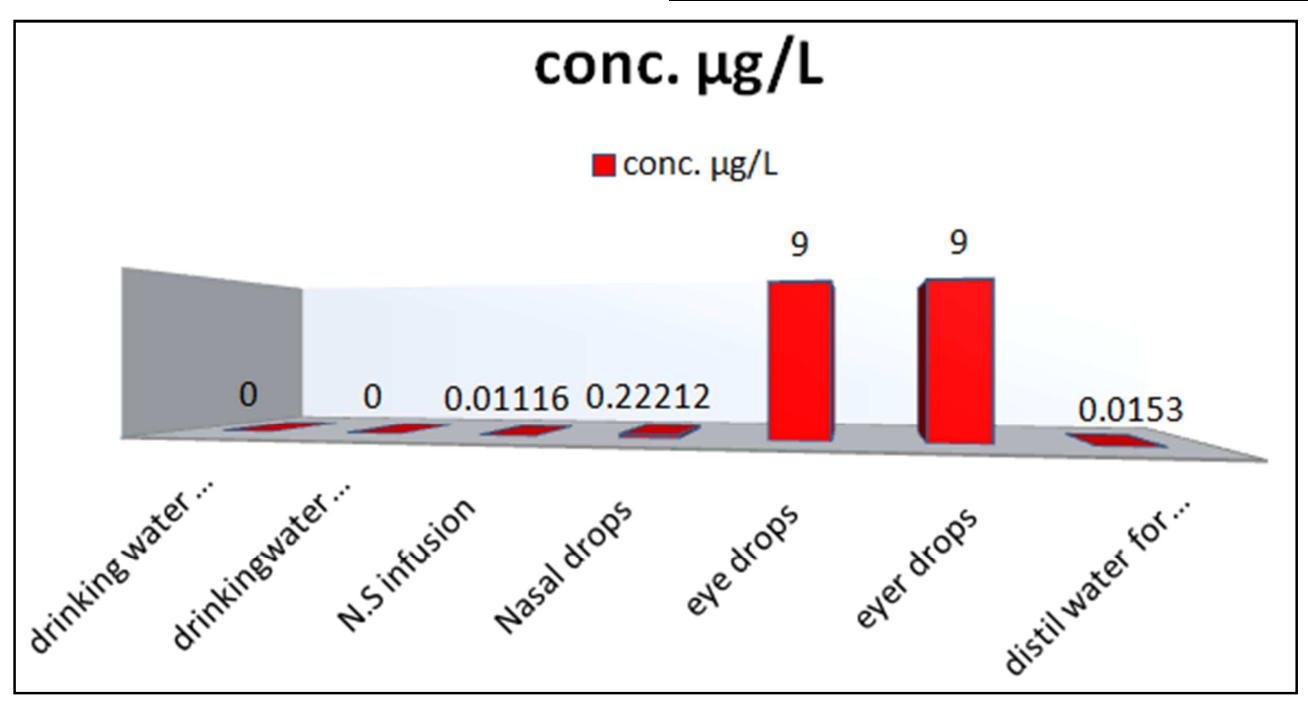

Figure 1: Amount of BPA $\mu g / L$ in drugs /water container.

\subsection{Discussion}

The volatility and thermal stability presented by Bisphenol A make it suitable for detection by spectrophotometer.There have been lots of researches on BPA detection using traditional analytical methods or immune enzymatic methods such as mass spectroscopy [26][27], high performance liquid chromatography[28], UV-vis spectrophotometry [29] and enzyme-linked immune sorbent assay [30].This study made to detection BPA in drugs and drinking water container, Early studies show that amount of BPA found in food container (polyethylene container)- Polycarbonate infant feeding bottles and drinking bottles. Migration from new 
bottles is very low, but can increase with repeated use, due to cleaning treatments [31].Epoxy resin coatings of canned foods. BPA is more likely to migrate into oily or fatty foods, such as meat, fish and coconut cream [32].

\section{Conclusion}

The study above is not proposing any changes to our risk assessment opinion at this point in time, as the clear weight of scientific evidence, from an extensive range of studies and risk assessments undertaken over a considerable period of time, indicates that BPA found in drugs container and water drinking bottle represent a significant human health risk. Combined with the industry initiatives to phase out the use of BPA in Polycarbonate water/ container and various food containers, the low levels of exposure are likely to decrease even further.

\section{References}

[1] "Chemical Fact Sheet - Cas \# 80057 CASRN 80-05-7". Speclab.com. 1 April 2012.

[2] (Dianin) (1891). [On condensation products of ketones with phenols]. (Journal of the Russian Physical-Chemical Society) 23: 488-517, 523-546, 601-611. See especially p. 492.

[3] Zincke T (1905). "Ueber die Einwirkung von Brom und von Chlor auf Phenole: Substitutionsprodukte, Pseudobromide und Pseudochloride". Justus Liebigs Annalen der Chemie 343: 7599. doi: 10.1002/jlac.19053430106.

[4] Uglea, Constantin V.; Ioan I. Negulescu (1991). Synthesis and Characterization of Oligomers. CRC Press. p. 103. ISBN 08493-4954-0.

[5] 7. Fiege H, Voges H-W, Hamamoto T, Umemura S, = Iwata T, Miki H, Fujita Y, Buysch H-J, = Garbe D, Paulus W (2002). Phenol Derivatives. Ullmann's Encyclopedia of Industrial Chemistry. Ullmann's Encyclopedia of Industrial Chemistry (Weinheim: Wiley-VCH). doi:10.1002/14356007.a19_313

[6] "Experts demand European action on plastics chemical". Reuters. 22 June 2010.

[7] National Toxicology Program, U.S. Department of Health and Human Services (September 2008). "CERHR Expert Panel Report for Bisphenol A" (PDF). Retrieved May 2013.

[8] "Bisphenol A Action Plan" (PDF). U.S. Environmental Protection Agency. 29 March 2010. Retrieved 12 April 2010.

[9] "Concern over canned foods". Consumer Reports. December 2009. Retrieved2 February 2012.

[10] "Bisphenol A Information Sheet" (PDF). Bisphenol A Global Industry Group. October 2002. Retrieved 7 December 2010.

[11] "Studies Report More Harmful Effects From BPA". U.S. News \& World Report. 10 June 2009. Retrieved 28 October 2010 .

[12] Replogle J (17 July 2009). "Lawmakers to press for BPA regulation". California Progress Report. Retrieved 31 January 2012.
[13] Ubelacker, Sheryl (16 April 2008). "Ridding life of bisphenol A a challenge". Toronto Star. Retrieved 2 August 2009.

[14] US 6562755, "Thermal paper with security features" Raloff, Janet (7 October 2009). "Concerned about BPA: Check your receipts". Science News. Retrieved 3 August 2010.

[15] "A Survey of Bisphenol A in U.S. Canned Foods". Environmental Working Group. 5 March 2007. Retrieved 2 February 2012.

[16] Health Canada. "Survey of Bisphenol A in Canned Drink Products". Retrieved13 March 2009.

[17] Erickson BE (2 June 2008). "Bisphenol A under scrutiny". Chemical and Engineering News (American Chemical Society) 86 (22): 36-39. doi: 10.1021/cen-v086n022. p036.

[18] Rubin BS (2011)." Bisphenol A: An endocrine disruptor with widespread exposure and multiple effects". J. Steroid Biochem. Mol. Bio 127 (1-2): 27-34. doi: 10.1016/j.jsbmb. 2011.05.002. PMID 21605673.

[19] Gore AC (8 June 2007). Endocrine - Disrupting Chemicals: From Basic Research to Clinical Practice. Contemporary Endocrinology. Humana Press. ISBN 978-1-58829-830-0.

[20] O'Connor JC, Chapin RE (2003). "Critical evaluation of observed adverse effects of endocrine active substances on reproduction and development, the immune system, and the nervous system" (PDF). Pure Appl. Chem 75 (11-12): 20992123.doi: 10.1351/pac200375112099. Retrieved 28 February 2007.

[21] Okada H, Tokunaga T, Liu X, Takayanagi S, Matsushima A, Shimohigashi Y (January 2008). "Direct evidence revealing structural elements essential for the high binding ability of bisphenol A to human estrogen-related receptor-gamma". Environ. Health Perspect.116 (1): 32-8. doi: 10.1289/ehp.10587. PMC 2199305. PMID 18197296.

[22] vomSaal FS, Myers JP (2008). "Bisphenol A and Risk of Metabolic Disorders". JAMA 300 (11): 1353-5. doi: 10.1001/jama.300.11.1353. PMID 18799451

[23] Ginsberg G, Rice DC (2009). "Does Rapid Metabolism Ensure Negligible Risk from Bisphenol A?". EHP 117 (11): 1639-1643. doi: 10.1289/ehp.0901010.PMC 2801165. PMID 20049111

[24] Beronius A, Rudén C, Håkansson H, Hanberg A (2010). "Risk to all or none? A comparative analysis of controversies in the health risk assessment of BisphenolA". Reproductive toxicology (Elmsford, N.Y.) 29 (2): 132-46. doi: 10.1016/j.reprotox.2009.11.007. PMID 19931376

[25] Brock, J. W., Yoshimura, Y., Barr, J. R., Maggio, V. L., Graiser, S. R., Nakazawa, H., Needham, L. L., 2001. Journal of Exposure Analysis and Environmental Epide- miology 11, 323-328.

[26] Kim, H., Hong, J. K., Kim, YH., Kim, K. R., 2003. Archives of Pharmacal Research 26, 697-705.

[27] Noda, M., Komatsu, H., Sano, H., 1999. Journal of Biomedical Materials Research 47, 374-378.

[28] Poorahong, S., Thammakhet, C., Thavarungkul, P., Kanatharana, P., 2012. Journal of Environmental Science and Health, Part A 48, $242-250$. 
[29] De Meulenaer, B., Baert, K., Lanckriet, H., VanHoed, V., Huyghebaert, A., 2002. Journal of Agricultural and Food Chemistry 50, 5273-5282.

[30] Environment Canada. (2008). Draft screening assessment for phenol, 4, 4' - (1- methylethyllidene) bis - (80-05-7). Accessed at:

http://www.ec.gc.ca/substances/ese/eng/challenge/batch2/batc h2_80-05-7.cfm. Accessed: 14 October.

[31] Scientific Panel on Food Additives Flavourings Processing
Aids and Materials in Contact with Food. (2006) Opinion of the Scientific Panel on Food Additives, Flavourings, Processing Aids and Materials in Contact with Food on a request from the Commission related to 2, 2-bis(4hydroxyohenyl)propane (Bisphenol A). EFSA Journal; 428: 175 .

[32] Thomson BM, Grounds PR. (2005) Bisphenol A in canned foods in New Zealand: Anexposure assessment. Food Additives \& Contaminants: Part A; 22(1): 65 - 72. 